\title{
Exposure to permethrin or chlorpyrifos causes differential dose- and time-dependent behavioral effects at early larval stages of an endangered teleost species
}

\author{
Paige C. Mundy ${ }^{1}$, Kara E. Huff Hartz ${ }^{2}$, Corie A. Fulton ${ }^{2}$, Michael J. Lydy ${ }^{2}$, \\ Susanne M. Brander ${ }^{3}$, Tien-Chieh Hung ${ }^{4}$, Nann A. Fangue ${ }^{5}$, Richard E. Connon ${ }^{1, *}$ \\ ${ }^{1}$ Anatomy, Physiology \& Cell Biology, School of Veterinary Medicine, University of California, Davis, Davis, CA 95616, USA \\ ${ }^{2}$ Center for Fisheries, Aquaculture and Aquatic Sciences and Department of Zoology, Southern Illinois University, \\ Carbondale, IL 62901, USA \\ ${ }^{3}$ Department of Fisheries and Wildlife, Coastal Oregon Marine Experiment Station, Oregon State University, Corvallis, \\ OR 97331, USA \\ ${ }^{4}$ Fish Conservation and Culture Laboratory, Department of Biological and Agricultural Engineering, \\ University of California, Davis, Davis, CA 95616, USA \\ ${ }^{5}$ Department of Wildlife, Fish \& Conservation Biology, University of California, Davis, Davis, CA 95616, USA
}

\begin{abstract}
Pyrethroid and organophosphate pesticides are two of the most commonly used classes of insecticide worldwide. At sublethal concentrations, permethrin (a pyrethroid) and chlorpyrifos (an organophosphate) impact behavior in model fish species. We investigated behavioral effects of environmentally relevant concentrations of permethrin or chlorpyrifos on early larval delta smelt Hypomesus transpacificus, a Critically Endangered teleost species endemic to the San Francisco Bay Delta, California, USA. Using a photomotor behavioral assay of oscillating light and dark periods, we measured distance moved, turn angle, meander, angular velocity, rotations, thigmotaxis (time spent in the border versus center), and swim speed duration and frequency. The lowest concentrations of permethrin used in the tests $\left(0.05\right.$ and $\left.0.5 \mu \mathrm{g} \mathrm{l}^{-1}\right)$ caused significant increases in distance moved at 72 and $96 \mathrm{~h}$, respectively. At 48, 72, and $96 \mathrm{~h}$ of exposure, $5 \mu \mathrm{g} \mathrm{l}^{-1}$ of permethrin caused a hyperactive state in which the larvae significantly decreased thigmotaxis, quickly turning in short bouts of activity, characterized by significant increases in rotations and freezing events. Larvae exposed to $0.05 \mathrm{\mu g} \mathrm{l}^{-1}$ chlorpyrifos significantly increased thigmotaxis at 72 and $96 \mathrm{~h}$. In response to $5 \mu \mathrm{g} \mathrm{l^{-1 }}$ chlorpyrifos, larvae significantly increased velocity at $72 \mathrm{~h}$ exposure, and significantly increased freezing events at $96 \mathrm{~h}$. Behavioral data on larval delta smelt exposed to contaminants present in their limited habitat have the potential to aid evaluations of the suitability of spawning and rearing habitats for this endangered species, thus improving conservation management strategies focused on this sensitive life stage.
\end{abstract}

KEY WORDS: Delta smelt - Hypomesus transpacificus · Behavioral toxicology · Pyrethroid · Organophosphate

\section{INTRODUCTION}

Two of the most common insecticide groups used worldwide are pyrethroids and organophosphates. Application and use of pyrethroid pesticides have grown

${ }^{*}$ Corresponding author: reconnon@ucdavis.edu

$\S_{\text {Corrections }}$ were made after publication. For details see www.int-res.com/abstracts/esr/v44/c_p89-103/

This corrected version: March 4, 2021 in popularity in agricultural and urban sectors (Kuivila et al. 2012, Weston \& Lydy 2012, Deanovic et al. 2018, Tang et al. 2018). Although domestic use of organophosphates has decreased due to a household ban in the USA in 2000, they are still heavily used in agricul-

( ) The authors 2021. Open Access under Creative Commons by Attribution Licence. Use, distribution and reproduction are unrestricted. Authors and original publication must be credited. 
ture (Mackay et al. 2014, DiBartolomeis et al. 2019). Both categories of insecticide are of concern to aquatic organisms, and have been shown to be particularly toxic to fish (Giesy et al. 1999, Weston et al. 2015b).

Permethrin is among the most commonly detected pyrethroids in environmental and organismal samples (Tang et al. 2018). Because permethrin is used heavily in agricultural and urban applications, it often enters watersheds and can be found in sediment and surface waters in the ng $\mathrm{l}^{-1}$ to $\mathrm{\mu g} \mathrm{l}^{-1}$ range (You \& Lydy 2006, Delgado-Moreno et al. 2011, Weston et al. 2014, Deanovic et al. 2018). Pyrethroids are classified as Type I or Type II according to their chemical structure. Permethrin is considered a Type I pyrethroid insecticide, as it lacks an $\alpha$-cyano group on the phenoxybenzyl moiety (Soderlund 2012). The mechanism of action (MOA) of permethrin is generally accepted to be the binding of voltage gated sodium ion channels (VGSCs), delaying closure of the channel, resulting in prolonged depolarization of neurons, ultimately resulting in convulsions and death (Soderlund 2012). At the whole-organism level, exposure to permethrin elicits the neurotoxic effect of tremors in mammals (Soderlund 2012, Hughes et al. 2016, Gammon et al. 2019). Pyrethroid metabolism may be species-specific (Glickman \& Lech 1981), possibly contributing to the differences in tolerance between mammals and fish. At sublethal concentrations, permethrin is found to induce hyperactivity in larval fish; for example, visible spasms have been observed in zebrafish larvae at $50 \mathrm{\mu g} \mathrm{l}^{-1}$ (DeMicco et al. 2010). Larval zebrafish Danio rerio exposed to $25 \mathrm{\mu g} \mathrm{l}^{-1}$ permethrin decreased thigmotaxis, defined here as the affinity of an organism to preferentially remain near the boundaries of an environment, as opposed to the center (Nunes et al. 2020). Thigmotaxis has been observed in other fish species (Millot et al. 2009, Sharma et al. 2009), and can be used as a measure of anxiety in larval fish. Exposure of larval zebrafish to anxiolytic or anxiogenic compounds has been found to enhance or attenuate thigmotaxis, respectively (Schnörr et al. 2012).

Chlorpyrifos is an organophosphate pesticide, commonly used worldwide in agricultural settings (Mackay et al. 2014, Solomon et al. 2014). Because it is used heavily in the agricultural sector, it often enters watersheds, particularly after storm events, and can be found in sediment as well as surface waters (DelgadoMoreno et al. 2011, Williams et al. 2014, Weston et al. 2015a, Deanovic et al. 2018). The MOA of chlorpyrifos (in both mammals and fish) is inhibition of acetylcholinesterase, leading to accumulation of acetylcholine in the synaptic junction of neurons, ultimately causing repeated stimulation of neurons and nervous system malfunction (Giesy et al. 1999, Eaton et al. 2008). At the whole-organism level, this can lead to uncontrollable muscle twitches or spasms, eventually resulting in muscle weakness, or respiratory muscle dysfunction and/or paralysis, ultimately causing death (Jokanović \& Kosanović 2010). Developmental exposure to sublethal concentrations of chlorpyrifos can cause hyperactivity and impaired choice accuracy in rats (Levin et al. 2002). Behavioral impairment observed in fish due to sublethal chlorpyrifos exposure includes decreases in total distance moved during light-dark stimuli in zebrafish (Jin et al. 2015), impaired mobility in fathead minnow Pimephales promelas larvae (Belden \& Lydy 2006), as well as decreased swimming speed in zebrafish larvae (Richendrfer \& Creton 2015) and adult medaka Oryzias latipes (Sastre et al. 2018). Zebrafish larvae exposed to chlorpyrifos have also been found to decrease thigmotaxis (Richendrfer et al. 2012, Richendrfer \& Creton 2015).

During fish development, early larval stages are especially vulnerable to perturbations by abiotic insults, including pesticide exposures (Ramos et al. 2012). Determining the sensitivity of fish larvae to sublethal pesticide exposures is essential when assessing risks, particularly in environmental management, as these could lead to potential impacts at the population level. The delta smelt Hypomesus transpacificus is a euryhaline teleost species that is endemic to the San Francisco Bay Delta (SFBD). Listed as endangered species under both Federal and California State Endangered Species Acts (listed as threatened in 1993; USFWS 1993, and as endangered in 2010; CDFW 2018), delta smelt abundance has rapidly declined since the mid-1980s, and is at risk of extinction (Hobbs et al. 2017).

Delta smelt are often acclaimed as an indicator of the environmental health of the SFBD; therefore, swift drops in population abundance suggest that the ecosystem is transforming inordinately (Lessard et al. 2018). Climate change and anthropogenic manipulation of water flows are known to be drivers of change in the SFBD (Cayan et al. 2008, Cloern \& Jassby 2012). Physical habitat factors, such as these, correlate strongly with the limits of habitat range in delta smelt (Brown et al. 2016). However, information regarding the impact of contaminants on early life stages of delta smelt is limited. Both permethrin and chlorpyrifos have been measured in areas inhabited by delta smelt (Weston et al. 2014, 2015a), and both have been measured at concentrations as high as the $\mu \mathrm{g}^{-1}$ range in the SFBD, including in agricultural drainage areas adjacent to habitats in which delta smelt have been sampled (Zhang et al. 2012, Deng 2017). 
One anticipated conservation goal for the delta smelt is the re-introduction of the captive refuge population into the wild (Hobbs et al. 2017, Lessard et al. 2018). The application of toxicology tests, which can be conducted under controlled laboratory conditions, will serve to inform suitable locations for release, if embryos are to be considered as a suitable life stage for re-introduction. With the UC Davis Fish Conservation and Culture Laboratory (FCCL) functioning as a conservation hatchery for some listed fish species, including delta smelt, conducting robust laboratory tests on their larvae is an opportunity not afforded to most endangered teleost species due to lack of accessibility.

Behavioral tests can be powerful tools to assess the sublethal effects of chemical compounds. Particularly, high-throughput teleost larval behavior tests can allow a quick yet thorough characterization of effects resulting from exposure to numerous classes of compounds (Miller et al. 2018, Dach et al. 2019). We adapted a photomotor test typically used to evaluate zebrafish behavior (Miller et al. 2018, Dach et al. 2019) to specifically be applied to delta smelt larvae (Mundy et al. 2020). The test involves an oscillating cycle of dark and light, which we refer to as the light-dark (LD) cycle assay. In previous studies, we have confirmed that delta smelt larvae consistently move more in the light and less in the dark, and this pattern can be perturbed by the introduction of neurotoxic pesticides (Mundy et al. 2020). Here, we used the LD cycle assay to measure differences in behavior of delta smelt larvae by analyzing multiple endpoints including distance moved, turn angle, meander, angular velocity, rotations, thigmotaxis, velocity, and swim speed duration and frequency.

\section{MATERIALS AND METHODS}

\subsection{Fish source}

Procurement and maintenance of delta smelt larvae was completed using methods described in Mundy et al. (2020). In brief, for each pesticide exposure experiment, delta smelt embryos were fertilized via strip spawning of 2 females and 2 males at the FCCL under the University of California Institutional Animal Care and Use Committee (IACUC) protocol no. 19841. Embryos were maintained at the FCCL according to their normal care conditions (freshwater and $16^{\circ} \mathrm{C}$ ) until 7 days post fertilization (dpf) (Lindberg et al. 2013). At 7 dpf, embryos were transported to the exposure lab at UC Davis campus. Research conducted on early larval stages was approved by IACUC protocol no. 20705.

\subsection{Chemical information}

Larvae were exposed to nominal concentrations of $0.05,0.5$, and $5 \mu \mathrm{g} \mathrm{l}^{-1}$ of permethrin $(99.5 \%$ purity, ChemService, CAS: 52645-53-1, product no. N12848-250MG) or chlorpyrifos (99.4\% purity, ChemService, West Chester, PA, USA. CAS: 2921-88-2, product no. N-11459-250MG). The concentration ranges were chosen to reflect environmentally relevant concentrations found in the SFBD and its tributaries (California, USA). Methanol (Fisher Scientific), not exceeding $0.02 \% \mathrm{v} / \mathrm{v}$, was used as a vehicle solvent carrier for permethrin, while acetone (Fisher Scientific), not exceeding $0.02 \% \mathrm{v} / \mathrm{v}$, was used as a vehicle solvent carrier for chlorpyrifos.

Permethrin and chlorpyrifos concentrations were measured in exposure water to confirm the nominal concentrations at the beginning of each test. The pesticides were extracted from exposure water by reversed-phase solid-phase extraction (Wang et al. 2009), and quantified using an Agilent chromatograph with a 5975-mass selective detector (MSD; Agilent Technologies) and negative chemical ionization (NCI). A complete description of the method can be found in the Supplement (Methods, Table S1) at www.int-res. com/articles/suppl/n044p089_supp.pdf. The initial concentrations were in agreement with the nominal concentration $(<23 \%$ relative difference; Table S2 in the Supplement); therefore, the nominal concentrations are referenced for the remainder of the study.

\subsection{Larval fish exposure}

Compared to later life stages, larval fish are at a higher risk from exposure to lipophilic compounds, such as permethrin and chlorpyrifos, due to increased adsorption and uptake from the yolk sac. This early life stage also occurs during times of heavy rainfall, which flushes contaminants into their spawning habitat (Weston et al. 2019). For all of the tests, water quality was measured once on Day 1 (8 dpf) and once on the last day of the test (12 dpf). Temperature ranged from 16 to $16.4^{\circ} \mathrm{C}$ (Hanna Instruments), dissolved oxygen ranged from 9.82 to $10.43 \mathrm{mg} \mathrm{l}^{-1}$ (YSI), $\mathrm{pH}$ ranged from 8.55 to 8.61 (Hanna Instruments), salinity was 0.4 PSU (Hanna Instruments), and ammonia was $0 \mathrm{mg} \mathrm{l}^{-1}$ (API). Fifty percent of exposure water was renewed daily. 
Exposures were conducted using methods described in Mundy et al. (2020). In brief, embryos were randomly distributed into $200 \mathrm{ml}$ beakers filled with $100 \mathrm{ml}$ filtered $(0.22 \mu \mathrm{m})$ ground water with a stocking density of 20 per beaker. Embryos were placed in a temperature- and light-controlled chamber where they remained undisturbed until $8 \mathrm{dpf}$, and the start of the exposure test.

There were 4 exposure treatments - vehicle control and 3 pesticide concentrations - and 3 exposure durations (i.e. 48, 72, and 96 h). Each treatment (concentration and time) was replicated 6 times. The beakers were covered in parafilm (with several holes) to minimize evaporation, and larvae were left to acclimate in the beakers in a chamber held at $16^{\circ} \mathrm{C}$ and $24 \mathrm{~h}$ darkness.

Exposures began at $8 \mathrm{dpf}$, approximately $24 \mathrm{~h}$ prior to hatch so that organisms hatched into the respective treatments. Throughout the exposure, 50\% of the medium was changed daily (renewed with appropriate treatment condition), at which time hatching and any mortality were also recorded. At 48, 72, and $96 \mathrm{~h}$ of exposure (corresponding to 10, 11, and 12 dpf), 3 larvae were removed from each replicate to perform behavioral testing ( $\mathrm{n}=15-18$ larvae per treatment) (see section 2.3). allowed to habituate in the dark for at least $5 \mathrm{~min}$. The temperature of the plate was kept at $16^{\circ} \mathrm{C}$ throughout the duration of the test via a recirculating water system attached to a chiller (TECO-US). Larvae were filmed from above, illuminated with programmable light from beneath the plate, set at 10000 lux for each light cycle and infrared (IR) light during dark periods. Tracking began with 10 min dark period (Dark 1), followed by 5 min light (Light 1), 10 min dark (Dark 2), 5 min light (Light 2), and a final 10 min dark period (Dark 3). All behavioral tests were conducted between 09:00 and 18:00 h.

\subsection{Parameters measured from the LD cycle assay}

The larvae in the videos were tracked via EthoVision XT software (version 14), measuring several outputs for each larva (Table 1) including total distance moved $(\mathrm{mm})$, velocity $\left(\mathrm{mm} \mathrm{s}^{-1}\right)$, absolute turn angle (deg), meander (deg $\mathrm{mm}^{-1}$ ), angular velocity (deg $\left.\mathrm{s}^{-1}\right)$, clockwise (CW) rotations, and counter-clockwise (CCW) rotations, all binned by minute.

The measured velocities were binned by speed into several categories including cruising $\left(\geq 5 \mathrm{~mm} \mathrm{~s}^{-1}\right.$ and $\left.\leq 20 \mathrm{~mm} \mathrm{~s}^{-1}\right)$, bursting $\left(\geq 20 \mathrm{~mm} \mathrm{~s}^{-1}\right)$, and freezing

\subsection{Behavioral assessment of pesticide-exposed larvae}

In a previous study, we developed the LD cycle behavioral test that leveraged the observed natural photomotor response of the larvae (Mundy et al. 2020). At the age of interest $(10,11$, and $12 \mathrm{dpf}), 3$ larvae from each replicate of each exposure treatment were carefully placed into 3 individual wells of a (non-treated) 12-well cell culture plate (Thermo Fisher no. 150200) containing $2 \mathrm{ml}$ of water at specific target pesticide concentrations. Each ( $\mathrm{n}=15-18$ larvae per treatment) plate was randomized such that it contained 3 larvae from each respective pesticide treatment. The larvae were allowed to adjust to the plate conditions for at least $1 \mathrm{~h}$ before placing the plate into a DanioVision Observation Chamber. Once placed in the chamber, larvae were
Table 1. Variables measured in the light-dark (LD) cycle assay

\begin{tabular}{|c|c|c|}
\hline Measurement & Unit & Calculation \\
\hline Total distance moved & $\mathrm{mm}$ & Per minute, binned by cycle \\
\hline Thigmotaxis & portion & $\begin{array}{l}\text { Total seconds tracked per minute } \\
\text { divided by seconds spent in border } \\
\text { or center, binned by cycle }\end{array}$ \\
\hline Turn angle & Degree $\left({ }^{\circ}\right)$ & Per minute, binned by cycle \\
\hline Meander & ${ }^{\circ} \mathrm{mm}^{-1}$ & Per minute, binned by cycle \\
\hline Angular velocity & ${ }^{\circ} \mathrm{s}^{-1}$ & Per minute, binned by cycle \\
\hline Clockwise rotations & Count & Per minute, binned by cycle \\
\hline Counter-clockwise rotations & Count & Per minute, binned by cycle \\
\hline Velocity & $\mathrm{mm} \mathrm{s}^{-1}$ & Per minute, binned by cycle \\
\hline $\begin{array}{l}\text { Cruising duration } \\
\left(\geq 5 \mathrm{~mm} \mathrm{~s}^{-1} \& \leq 20 \mathrm{~mm} \mathrm{~s}^{-1}\right)\end{array}$ & $\mathrm{s}$ & $\begin{array}{l}\text { Seconds spent at that speed per } \\
\text { minute, binned by cycle }\end{array}$ \\
\hline $\begin{array}{l}\text { Cruising frequency } \\
\left(\geq 5 \mathrm{~mm} \mathrm{~s}^{-1} \& \leq 20 \mathrm{~mm} \mathrm{~s}^{-1}\right)\end{array}$ & Count & Counts per minute, binned by cycle \\
\hline $\begin{array}{l}\text { Bursting duration } \\
\left(\geq 20 \mathrm{~mm} \mathrm{~s}^{-1}\right)\end{array}$ & $\mathrm{s}$ & $\begin{array}{l}\text { Seconds spent at that speed per } \\
\text { minute, binned by cycle }\end{array}$ \\
\hline $\begin{array}{l}\text { Bursting frequency } \\
\left(\geq 20 \mathrm{~mm} \mathrm{~s}^{-1}\right)\end{array}$ & Count & Counts per minute, binned by cycle \\
\hline $\begin{array}{l}\text { Freezing duration } \\
\left(\leq 5 \mathrm{~mm} \mathrm{~s}^{-1}\right)\end{array}$ & $\mathrm{s}$ & $\begin{array}{l}\text { Seconds spent at that speed per } \\
\text { minute, binned by cycle }\end{array}$ \\
\hline $\begin{array}{l}\text { Freezing frequency } \\
\left(\leq 5 \mathrm{~mm} \mathrm{~s}^{-1}\right)\end{array}$ & Count & Counts per minute, binned by cycle \\
\hline
\end{tabular}


$\left(\leq 5 \mathrm{~mm} \mathrm{~s}^{-1}\right.$ ) using the EthoVision XT software. These speed categories were chosen to reflect categories measured in previous studies using zebrafish and fathead minnows (Steele et al. 2018), as well as preliminary studies using Delta smelt larvae (P.C. Mundy unpubl.). The categories were measured by duration (second per each minute at that speed) as well as frequency (number of times the larvae reached that speed per minute).

To measure thigmotaxis using the EthoVision software, each well was assigned an arena as the whole well (23 $\mathrm{mm}$ in diameter), where a smaller circle (the same size for each well) was assigned as the 'center' region of the well $(3.5 \mathrm{~mm}$ from the edge of well). The area outside the center region was termed the 'border' region. Time spent in each region was recorded $\left(\mathrm{s} \mathrm{min}^{-1}\right)$. The portion of time spent in the border area or center area was calculated in $\mathrm{R}$ (version 3.5.3) (R Core Team 2019) by dividing seconds recorded of larvae in the border or center area by total seconds recorded of larvae in the arena (binned by minute). All data were exported from EthoVision as Excel (xls) files, and processed in R for statistics and graphing.

\subsection{Statistics}

To determine differences in parameters measured in the LD cycle assays, averages were calculated and compared within the tests per cycle. Cycle refers to the periods of dark or light including Dark 1, Light 1, Dark 2, Light 2, and Dark 3. For all behavioral analysis tests, pairwise comparisons were made only with fish from within the same batch (each batch containing a clutch from 2 females and 2 males, outlined in Section 2.1). Fish were compared only within the same dpf (exposure time), and pesticide exposure (permethrin or chlorpyrifos). Parameters were compared within each cycle (Dark 1, Light 1, etc.), and only between cycles for Fig. S1 in the Supplement. For all behavior assays, a nonparametric KruskalWallis ANOVA was run to test the effects of pesticide treatment on the measured parameter using the kruskal_test function in R (Kassambara 2020). As post hoc analysis, contrasts were assessed via emmeans multiple comparison test in R (Lenth 2019), using the contrast method (control versus treatment) to compare vehicle control with the $0.05,0.5$, and $5 \mu \mathrm{g} \mathrm{l}^{-1}$ permethrin or chlorpyrifos treatments $(\alpha<$ 0.05 ). The $p$-value was adjusted using the dunnetx method (Dunnett's test) for 3 tests (vehicle control versus the $0.05,0.5$, and $5 \mu \mathrm{g} \mathrm{l}^{-1}$ permethrin or chlor- pyrifos treatments). To measure differences in movement between cycles for each pesticide at each exposure time (Fig. S1), the Dunn's multiple comparisons test was utilized via the dunns function in R (Kassambara 2020). While presenting multiple parameters having different units (i.e. $\mathrm{mm} \mathrm{s}^{-1}$, counts, and $\mathrm{s}_{i}$ in Figs. $1 \& 2$ ), the $Z$-score is presented, normalized to vehicle control to increase visual clarity. The calculation of the $Z$-score was conducted using the following equation: $Z=(x-\mu) / \sigma$, where $x$ is the value, $\mu$ is the mean, and $\sigma$ is the standard deviation.

To measure effects on total distance moved in a dose-responsive manner, the data were analyzed using regression analyses to fit concentration-effect curves based on an approach developed in Brander et al. (2016) and also applied in Frank et al. (2019) and Mundy et al. (2020). A maximum likelihood estimate (MLE) approach was used to evaluate whether non-monotonic curves were a better fit to the data than a null (intercept-only) model. Five different concentration-effect curves (linear regression, quadratic, sigmoidal, 5-parameter unimodal, and 6-parameter unimodal) were tested to fit responses of all 3 concentrations and vehicle control. A maximum likelihood ratio test was used to examine whether each curve provided a better fit than an intercept -only null model with a significance level of $\alpha<0.05$. All calculations for the concentration-effect curves were performed using mean total distance moved, rescaled between 0 and 1 within each cycle to facilitate comparison between pesticide concentration within each cycle. R scripts used for data preparation, statistical analysis, and graphing can be found at https:// github.com/insideafish/larvae_behavior.

\section{RESULTS}

\subsection{Effects of permethrin on larval delta smelt behavior}

Permethrin concentrations as low as $0.05 \mu \mathrm{g} \mathrm{l}^{-1}$ significantly impacted larval delta smelt behavior (Figs. 1A \& 2A), in that the larvae increased turning, as well as bursting frequencies and duration during the light periods. All statistically significant behavioral results are summarized in Table 2 . In brief, at 72 and $96 \mathrm{~h}$ of exposure to $5 \mu \mathrm{g} \mathrm{l^{-1 }}$, larvae moved significantly less in comparison to controls (Fig. 3A) during the light periods, and decreased thigmotaxis (Fig. 4A) as well as turning (Fig. 1A). Larvae exposed to $5 \mu \mathrm{l} \mathrm{l}^{-1}$ also exhibited increased bursting frequencies and freezing durations during the light periods (Fig. 2A). 


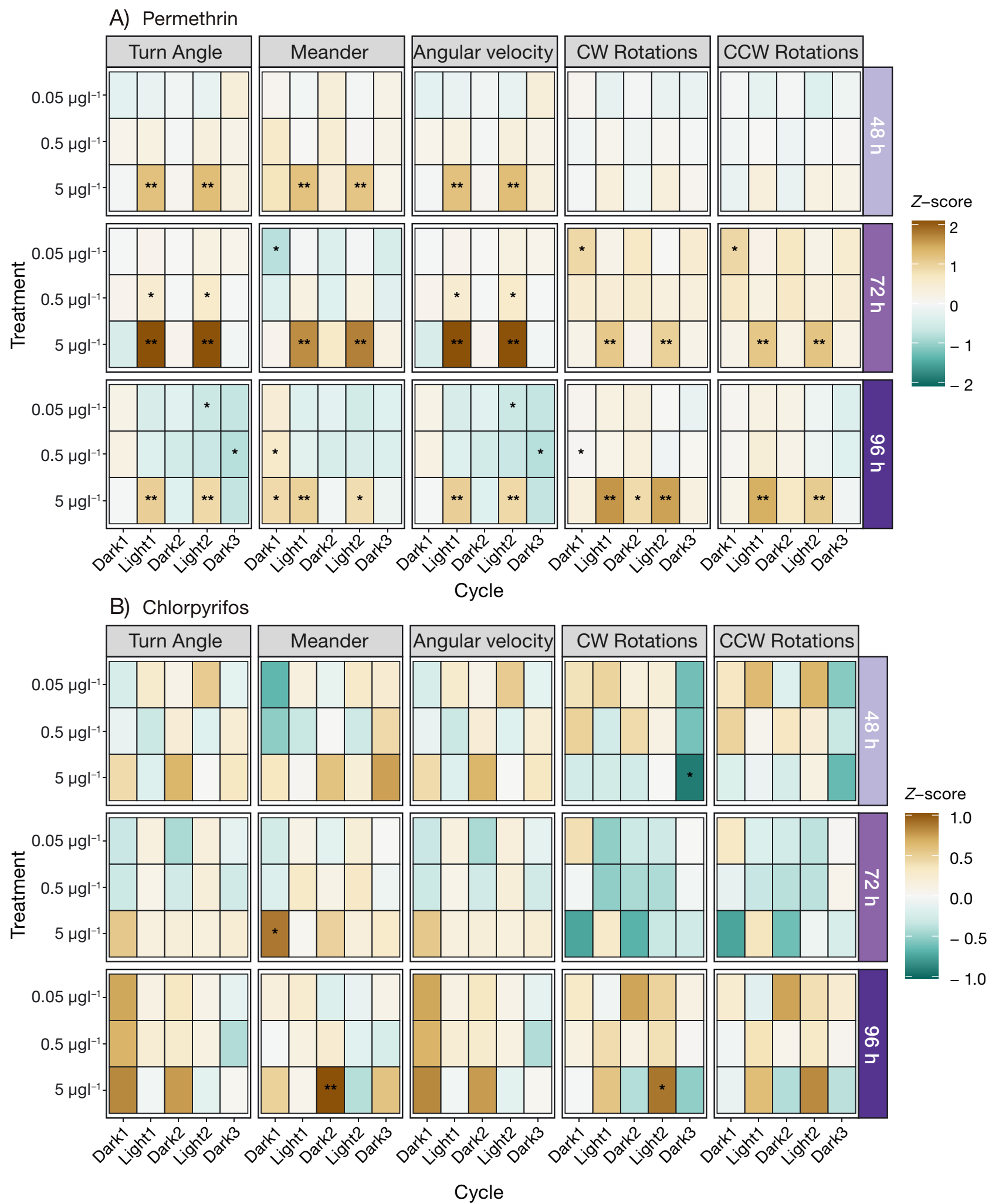

Fig. 1. Turning of delta smelt larvae exposed to (A) permethrin or (B) chlorpyrifos. Turn angle (deg), meander (deg mm ${ }^{-1}$ ), angular velocity $\left(\mathrm{deg} \mathrm{s}{ }^{-1}\right.$ ), clockwise $(\mathrm{CW})$ rotations, and counter-clockwise $(\mathrm{CCW})$ rotations are binned by minute and averaged over cycle. $Z$-score is presented for visual purposes, normalized to vehicle control. $\mathrm{n}=15-18$ larvae, ${ }^{*} \mathrm{p}<0.05$, ${ }^{* *} \mathrm{p}<0.01$ (Dunnett's test) 
A) Permethrin
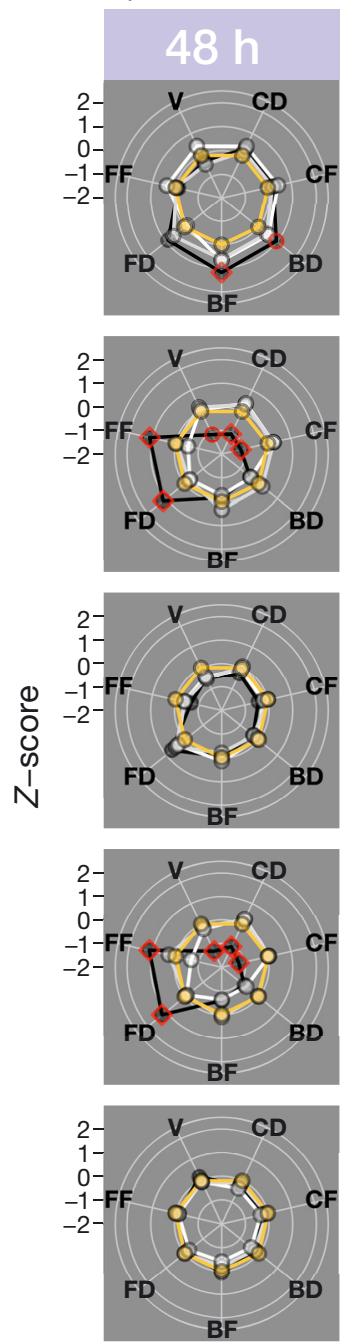

Radar plot map

Velocity 2 Cruising

1

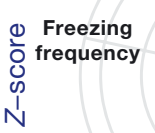

Freezing

duration

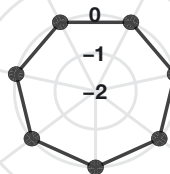

Cruising frequency
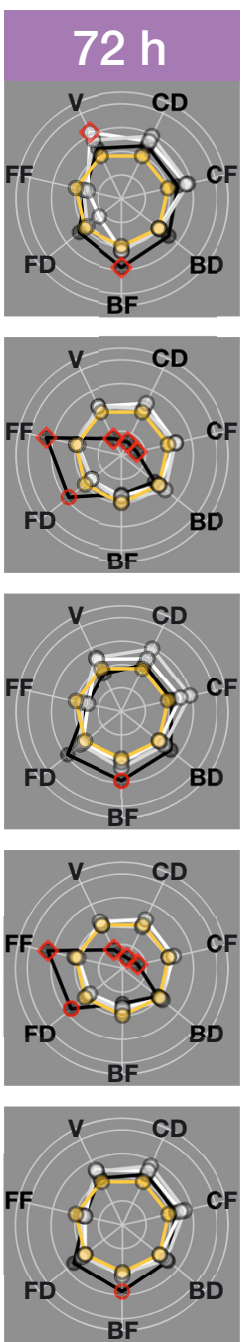

F
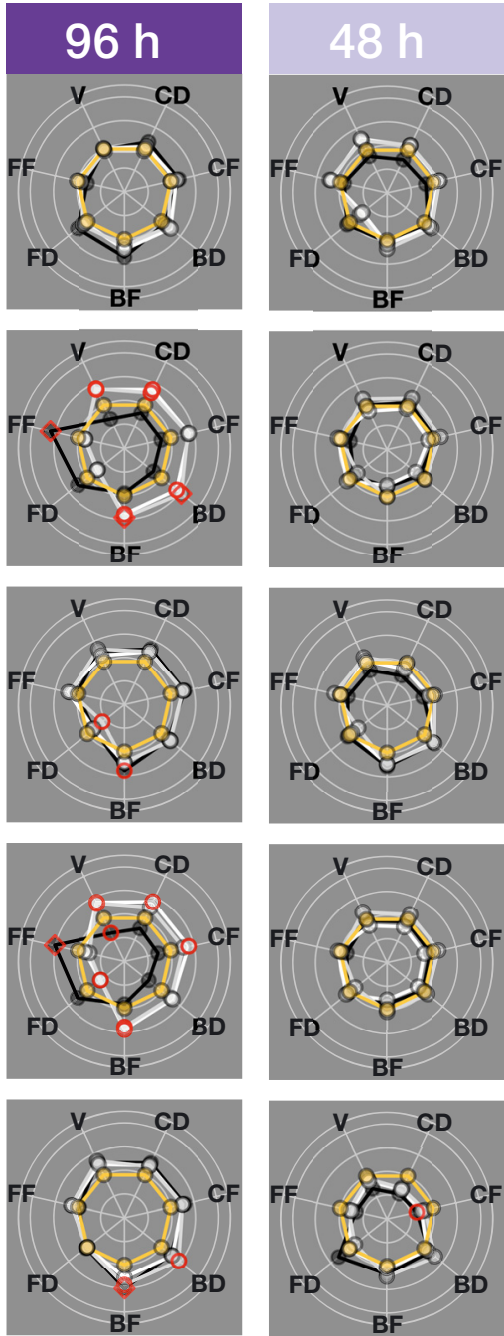

Parameter
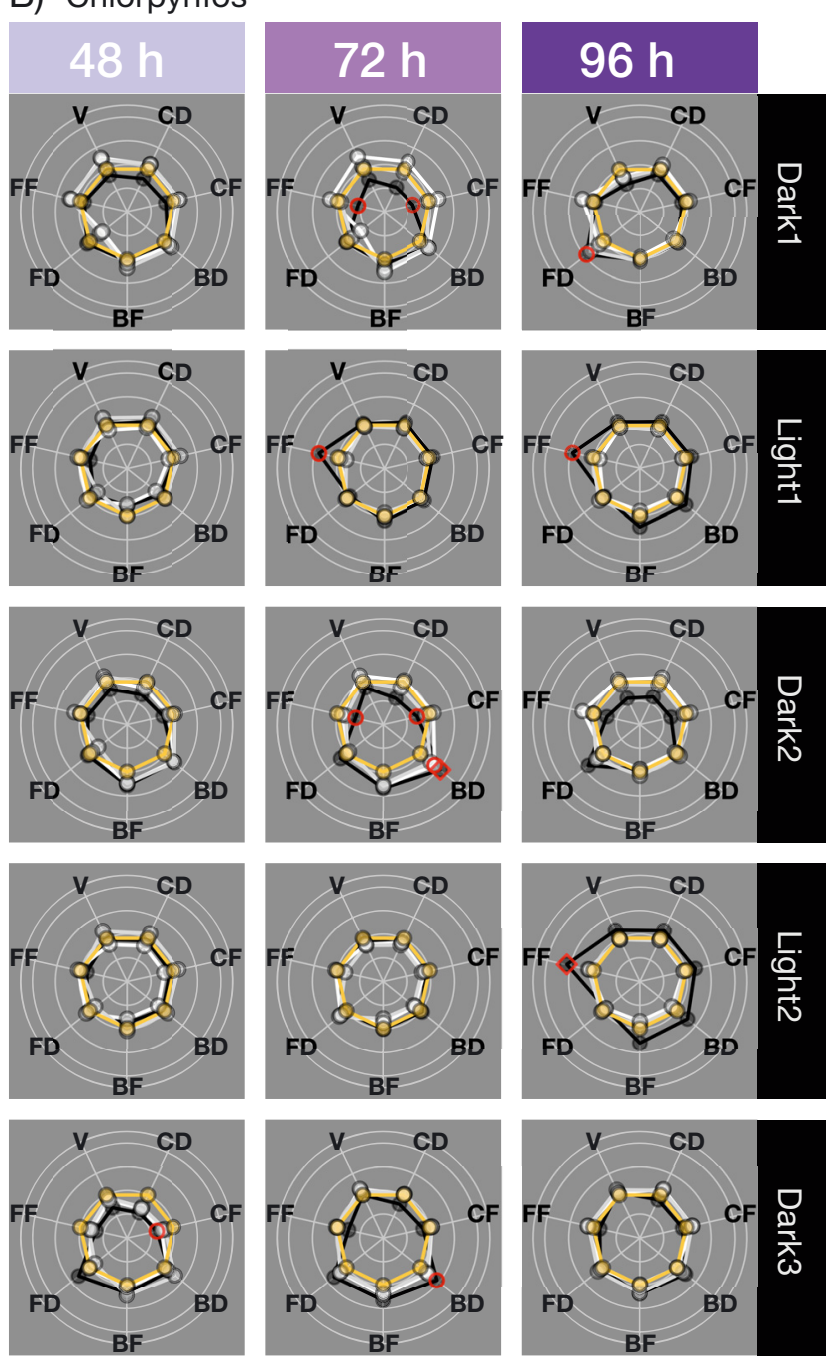
Table 2. Permethrin behavioral results. Arrows indicate direction of change in comparison to vehicle control ( $\uparrow$ increased or $\downarrow$ decreased). ${ }^{*} \mathrm{p}<0.05,{ }^{* *} \mathrm{p}<0.01$ (Dunnett's test)

\begin{tabular}{|c|c|c|c|c|c|c|c|}
\hline Parameter & $\begin{array}{l}\text { Exposure } \\
\text { time (h) }\end{array}$ & $\begin{array}{c}\text { Concentration } \\
\left(\mu \mathrm{g} \mathrm{l}^{-1}\right)\end{array}$ & Dark 1 & Light 1 & Dark 2 & Light 2 & Dark 3 \\
\hline Thigmotaxis & 48 & 0.05 & & & $\downarrow^{*}$ & & \\
\hline Meander & 72 & 0.05 & $\downarrow^{*}$ & & & & \\
\hline Clockwise rotations & 72 & 0.05 & $\uparrow *$ & & & & \\
\hline Counter-clockwise rotations & 72 & 0.05 & $\uparrow *$ & & & & \\
\hline Velocity & 72 & 0.05 & $\uparrow * *$ & & & & \\
\hline Turn angle & 96 & 0.05 & & & & $\downarrow *$ & \\
\hline Angular velocity & 96 & 0.05 & & & & $\downarrow *$ & \\
\hline Velocity & 96 & 0.05 & & $\uparrow *$ & & $\uparrow *$ & \\
\hline Cruising duration & 96 & 0.05 & & $\uparrow *$ & & $\uparrow *$ & \\
\hline Cruising frequency & 96 & 0.05 & & & & $\uparrow *$ & \\
\hline Bursting duration & 96 & 0.05 & & & & $\uparrow *$ & \\
\hline Bursting frequency & 96 & 0.05 & & $\uparrow *$ & & $\uparrow *$ & \\
\hline Thigmotaxis & 48 & 0.5 & & & $\downarrow *$ & & \\
\hline Turn angle & 72 & 0.5 & & $\uparrow *$ & & $\uparrow *$ & \\
\hline Angular velocity & 72 & 0.5 & & $\uparrow *$ & & $\uparrow *$ & \\
\hline Thigmotaxis & 96 & 0.5 & $\downarrow * *$ & & & & $\downarrow * *$ \\
\hline Turn angle & 96 & 0.5 & & & & $\downarrow *$ & $\downarrow^{*}$ \\
\hline Angular velocity & 96 & 0.5 & & & & $\downarrow *$ & $\downarrow *$ \\
\hline Velocity & 96 & 0.5 & & $\uparrow^{*}$ & & $\uparrow *$ & \\
\hline Cruising duration & 96 & 0.5 & & $\uparrow^{*}$ & & & \\
\hline Bursting duration & 96 & 0.5 & & $\uparrow * *$ & & & $\uparrow *$ \\
\hline Bursting frequency & 96 & 0.5 & & $\uparrow * *$ & & $\uparrow *$ & $\uparrow *$ \\
\hline Freezing duration & 96 & 0.5 & & & $\downarrow^{*}$ & $\downarrow^{*}$ & \\
\hline Thigmotaxis & 48 & 5 & $\downarrow$ ** & $\downarrow * *$ & & $\downarrow^{* *}$ & \\
\hline Turn angle & 48 & 5 & & $\uparrow * *$ & & $\uparrow * *$ & \\
\hline Meander & 48 & 5 & & $\uparrow * *$ & & $\uparrow * *$ & \\
\hline Angular velocity & 48 & 5 & & $\uparrow * *$ & & $\uparrow * *$ & \\
\hline Velocity & 48 & 5 & & $\uparrow *$ & & $\uparrow * *$ & \\
\hline Cruising frequency & 48 & 5 & & $\uparrow * *$ & & $\uparrow * *$ & \\
\hline Bursting duration & 48 & 5 & $\uparrow *$ & & & & \\
\hline Bursting frequency & 48 & 5 & $\uparrow * *$ & & & & \\
\hline Freezing duration & 48 & 5 & & $\uparrow * *$ & & $\uparrow * *$ & \\
\hline Freezing frequency & 48 & 5 & & $\uparrow * *$ & & $\uparrow * *$ & \\
\hline Distance moved & 72 & 5 & & $\downarrow * *$ & & $\downarrow^{*}$ & \\
\hline Thigmotaxis & 72 & 5 & $\downarrow$ ** & $\downarrow * *$ & $\downarrow^{* *}$ & $\downarrow * *$ & $\downarrow^{*}$ \\
\hline Turn angle & 72 & 5 & & $\uparrow * *$ & & $\uparrow * *$ & \\
\hline Meander & 72 & 5 & & $\uparrow * *$ & & $\uparrow * *$ & \\
\hline Angular velocity & 72 & 5 & & $\uparrow * *$ & & $\uparrow * *$ & \\
\hline Clockwise rotations & 72 & 5 & & $\uparrow * *$ & & $\uparrow * *$ & \\
\hline Counter-clockwise rotations & 72 & 5 & & $\uparrow * *$ & & $\uparrow * *$ & \\
\hline Velocity & 72 & 5 & & $\downarrow * *$ & & $\downarrow * *$ & \\
\hline Cruising duration & 72 & 5 & & $\downarrow * *$ & & $\downarrow * *$ & \\
\hline Cruising frequency & 72 & 5 & & $\downarrow^{* *}$ & & $\downarrow * *$ & \\
\hline Bursting duration & 72 & 5 & & & & & \\
\hline Bursting frequency & 72 & 5 & $\uparrow * *$ & & $\uparrow *$ & & $\uparrow *$ \\
\hline Freezing duration & 72 & 5 & & $\uparrow^{*}$ & & $\uparrow^{*}$ & \\
\hline Freezing frequency & 72 & 5 & & $\uparrow * *$ & & $\uparrow * *$ & \\
\hline Distance moved & 96 & 5 & & $\downarrow^{*}$ & & $\downarrow^{*}$ & \\
\hline Thigmotaxis & 96 & 5 & $\downarrow * *$ & $\downarrow * *$ & $\downarrow^{* *}$ & $\downarrow * *$ & $\downarrow^{* *}$ \\
\hline Turn angle & 96 & 5 & & $\uparrow * *$ & & $\uparrow * *$ & \\
\hline Meander & 96 & 5 & $\uparrow *$ & $\uparrow * *$ & & $\uparrow *$ & \\
\hline Angular velocity & 96 & 5 & & $\uparrow * *$ & & $\uparrow * *$ & \\
\hline Clockwise rotations & 96 & 5 & & $\uparrow * *$ & $\uparrow *$ & $\uparrow * *$ & \\
\hline Counter-clockwise rotations & 96 & 5 & & $\uparrow * *$ & & $\uparrow * *$ & \\
\hline Velocity & 96 & 5 & $\downarrow^{*}$ & & & & \\
\hline Bursting frequency & 96 & 5 & & & $\uparrow *$ & & $\uparrow * *$ \\
\hline Freezing frequency & 96 & 5 & & $\uparrow * *$ & & $\uparrow * *$ & \\
\hline
\end{tabular}




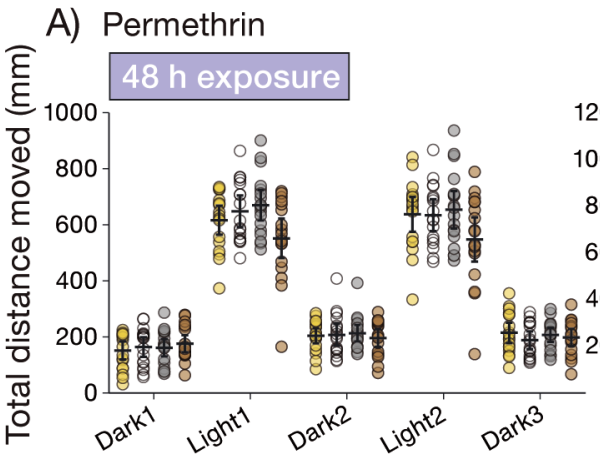

B) Chlorpyrifos

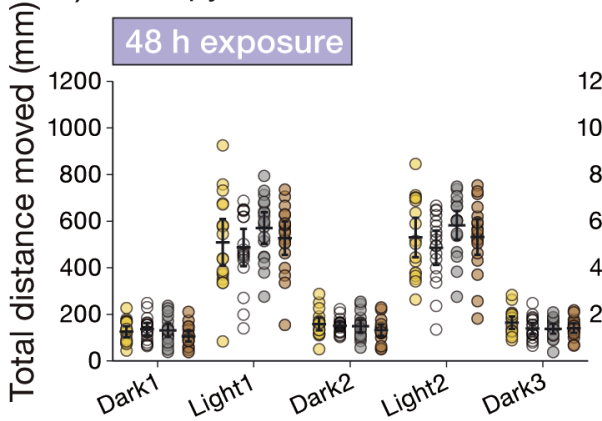

$72 \mathrm{~h}$ exposure

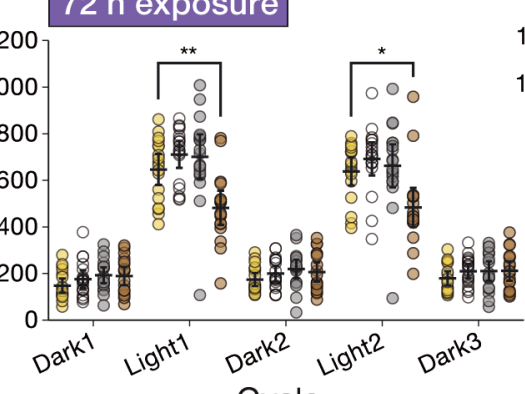

Cycle

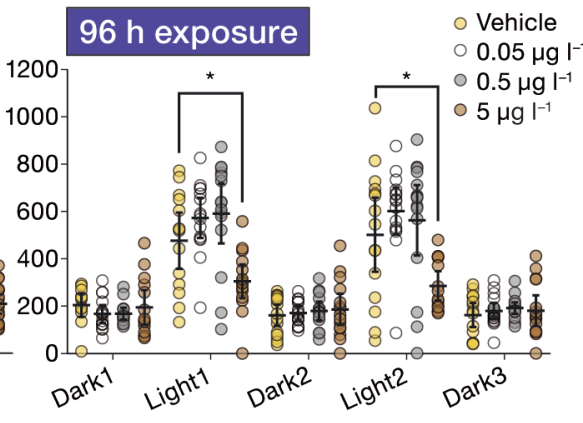

$0.05 \mu \mathrm{g} \mathrm{l}$

$05 \mu \mathrm{g} \mathrm{\textrm {I } ^ { - 1 }}$
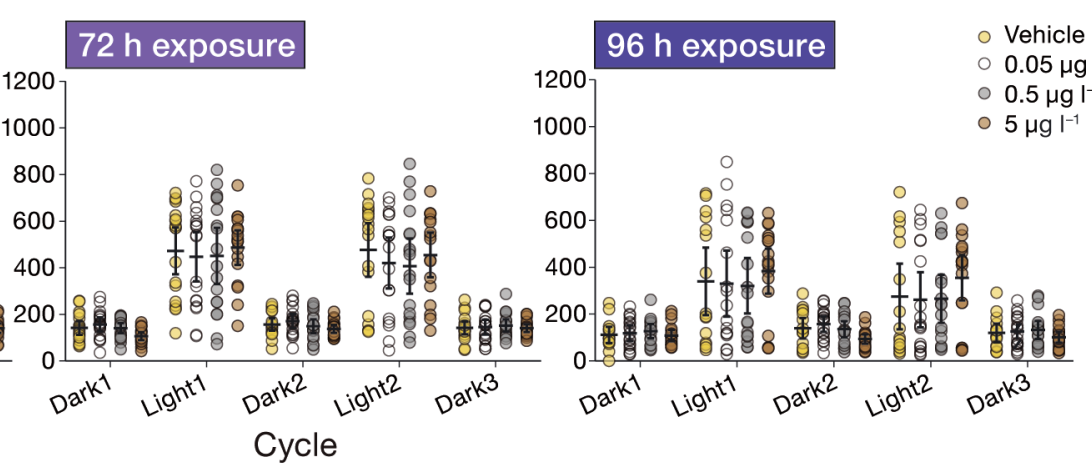

Fig. 3. Total distance moved in the light-dark (LD) cycle assay during exposure to (A) permethrin or (B) chlorpyrifos. Mean total distance moved over each cycle, of delta smelt larvae at 48, 72, or $96 \mathrm{~h}$ of exposure (which correspond to 10, 11, or 12 days post fertilization [dpf]). Individual points represent larvae $(\mathrm{n}=15-18)$, and bars represent mean and $95 \%$ confidence intervals. ${ }^{*} \mathrm{p}<0.05,{ }^{* *} \mathrm{p}<0.01$ (Dunnett's test, in comparison to vehicle control)

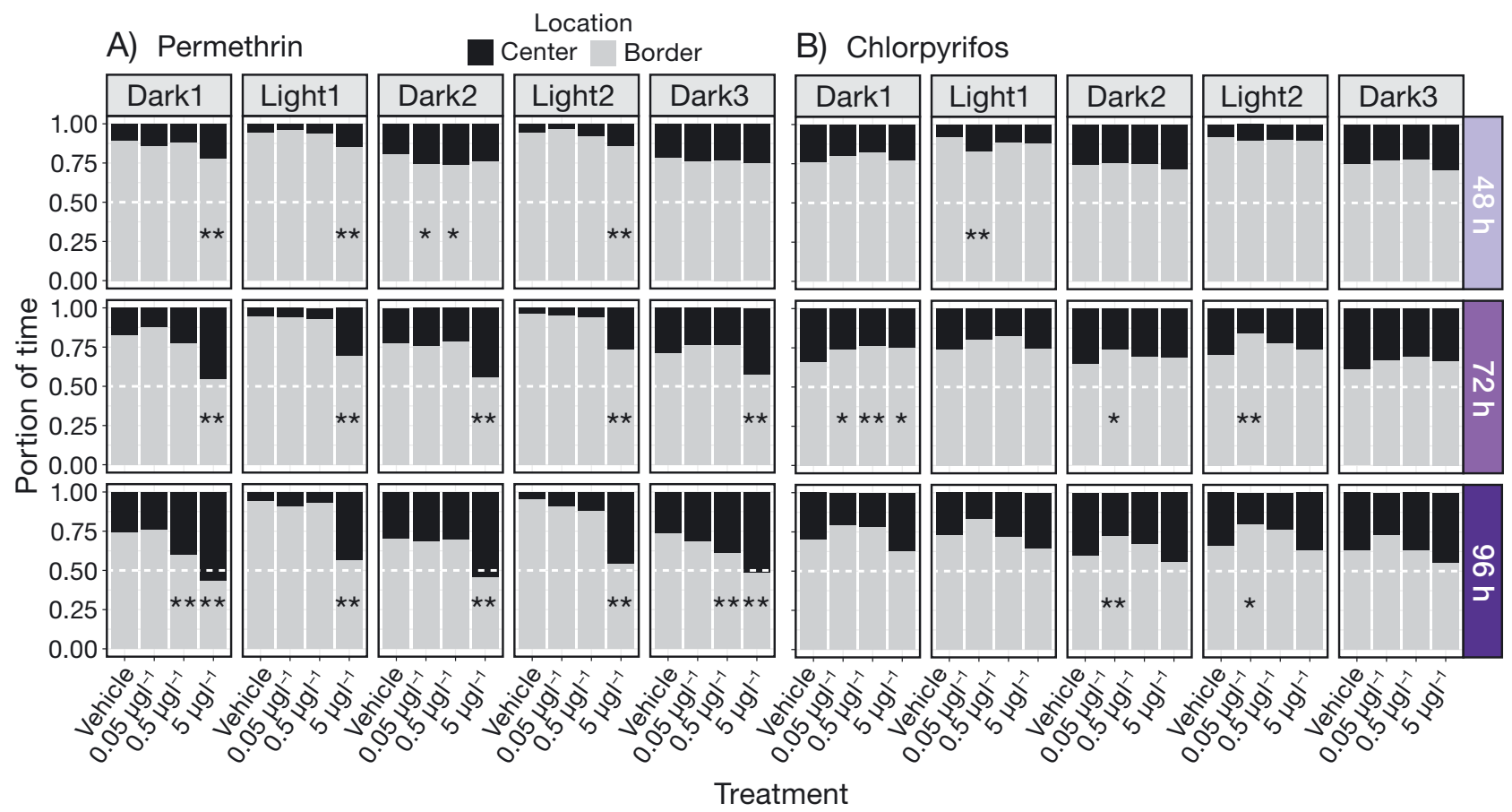

Fig. 4. Thigmotaxis of delta smelt larvae exposed to (A) permethrin or (B) chlorpyrifos. Portion of time spent in the border or center area of the well during the LD cycle assay. Portion of time calculated as seconds recorded of larvae in the border area, and seconds recorded in the center area, divided by seconds recorded of larvae in total, binned by minute and averaged over cycle. $\mathrm{n}=15-18$ larvae, ${ }^{*} \mathrm{p}<0.05,{ }^{* *} \mathrm{p}<0.01$ (Dunnett's test, in comparison to vehicle control) 
When each concentration was analyzed separately for differences in movement between cycles, almost all doses exhibited a paradigm in which the larvae move more during the light periods than in the dark periods ( $\mathrm{p}<0.05$, Dunn's $t$-test). Exceptions to this paradigm were observed in $96 \mathrm{~h}$ of exposure to $5 \mu \mathrm{g}$ $1^{-1}$ permethrin, in which no significant difference in total distance moved was observed between cycles (Fig. S1).

Additionally, the data exhibited non-monotonic responses, including quadratic (Light 1 of 48, 72, and $96 \mathrm{~h}$ and Light 2 of 48 and $72 \mathrm{~h}$ ) or sigmoidal (Light 2 of $96 \mathrm{~h}$ ) dose-response relationships during the light periods of the LD cycle assay $(p<0.05)$ (Fig. S2).

\subsection{Effects of chlorpyrifos on larval delta smelt behavior}

Chlorpyrifos concentrations as low as $0.05 \mu \mathrm{g} \mathrm{l}^{-1}$ significantly impacted larval delta smelt behavior (Fig. 4B) in that they increased thigmotaxis during the dark and light periods at $72 \mathrm{~h}$ of exposure. All statistically significant behavioral results are summarized in Table 3. Interestingly, more differences were observed in the dark periods than in the light periods. Larvae exposed to $5 \mu \mathrm{g}^{-1}$ for $72 \mathrm{~h}$ increased bursting durations and decreased cruising frequencies during dark periods, and increased freezing frequencies during the light periods at $96 \mathrm{~h}$ of exposure (Fig. 2B).

Movement of larvae between cycles per concentration consistently showed increased total distance moved in the light and decreased movement in the dark periods ( $\mathrm{p}<0.05$, Dunn's $t$-test). Exceptions to this paradigm were observed in $96 \mathrm{~h}$ of exposure to vehicle, 0.05 , or $0.5 \mu \mathrm{g} \mathrm{l^{-1 }}$ chlorpyrifos, in which no significant difference in total distance moved was observed between cycles (Fig. S1). When analyzed for dose-response, the data exhibited decreasing linear dose-response relationships during Dark 1 at $72 \mathrm{~h}$ and Dark 2 at 96 h (p<0.05) (Fig. S2)

\section{DISCUSSION}

The primary purpose of this investigation was to determine whether, and to what extent, exposure to environmentally relevant concentrations of permethrin or chlorpyrifos altered the behavior of early larval delta smelt. Several robust patterns of hyperactivity were exhibited by larvae exposed to 2 pesticides of different classes. The wide range of observed behavioral effects suggests that (1) contaminants known to be present in delta smelt habitats can alter larval behavior, and (2) the LD cycle assay can gather intricate yet comprehensive results relevant to physiological consequences of interaction with particular compounds as well as conservation efforts for delta smelt and other endangered teleost species.

The LD cycle assay is designed to be non-invasive, potentially eliminating confounding excess stress associated with handling, so as to effectively explore the minutiae of behavioral differences in these littlestudied larvae. This allows the quick yet thorough characterization of effects resulting from exposure to numerous classes of compounds. Although the para-

Table 3. Chlorpyrifos behavioral results. Arrows indicate direction of change in comparison to vehicle control (个increased or $\downarrow$ decreased). ${ }^{*} \mathrm{p}<0.05,{ }^{* *} \mathrm{p}<0.01$ (Dunnett's test)

\begin{tabular}{|c|c|c|c|c|c|c|c|}
\hline Parameter & Dark 1 & Light 1 & Dark 2 & Light 2 & Dark 3 & $\begin{array}{l}\text { Exposure } \\
\text { time (h) }\end{array}$ & $\begin{array}{c}\text { Concentration } \\
\left(\mu g \mathrm{l}^{-1}\right)\end{array}$ \\
\hline Thigmotaxis & & $\downarrow * *$ & & & & 48 & 0.05 \\
\hline Thigmotaxis & & & $\uparrow *$ & $\uparrow *$ & & 72 & 0.05 \\
\hline Thigmotaxis & & & $\uparrow *$ & $\uparrow *$ & & 96 & 0.05 \\
\hline Thigmotaxis & $\uparrow *$ & & & & & 48 & 0.5 \\
\hline Clockwise rotations & & & & & $\downarrow^{*}$ & 48 & 5 \\
\hline Cruising frequency & & & & & $\downarrow *$ & 48 & 5 \\
\hline Thigmotaxis & $\uparrow *$ & & & & & 72 & 5 \\
\hline Meander & $\uparrow *$ & & & & & 72 & 5 \\
\hline Cruising frequency & $\downarrow *$ & & $\downarrow^{*}$ & & & 72 & 5 \\
\hline Bursting duration & & & $\uparrow * *$ & & $\uparrow^{*}$ & 72 & 5 \\
\hline Freezing frequency & $\downarrow *$ & $\uparrow *$ & $\downarrow *$ & & & 72 & 5 \\
\hline Meander & & & $\uparrow * *$ & & & 96 & 5 \\
\hline Clockwise rotations & & & & $\uparrow *$ & & 96 & 5 \\
\hline Freezing duration & $\uparrow *$ & & & & & 96 & 5 \\
\hline Freezing frequency & & $\uparrow *$ & & $\uparrow * *$ & & 96 & 5 \\
\hline
\end{tabular}


meters (e.g. light cycle lengths and light intensity) of the LD cycle assay used in the present study were specific to eliciting the most robust and repeatable outcomes in delta smelt larvae (Mundy et al. 2020), the results can be applied outside of the delta smelt in the context of elucidating and describing the variety and mechanisms of effect of the compounds.

The way in which the data were collected and analyzed in the present study, consisting of 8 collected parameters, allows for a quantification of a behavioral pattern more complex and informative than the singular parameters themselves. For example, the hyperexcitability observed in response to the highest concentration $\left(5 \mu \mathrm{g} \mathrm{l}^{-1}\right)$ of permethrin during the light cycles consisted of the larvae spending more time in the center of the well, quickly turning and rotating in bouts of increased velocity (Figs. 1A, 2A, 4A). Although overall activity may suggest hypoactivity due to decreased total distance moved within the light cycles (Fig. 3A), the quantification and assessment of other variables (thigmotaxis, turning, and velocity) (Figs. 1A, 2A, 4A) reveal the hyperactive nature of the behavior. Decreases in total distance moved during stimulatory periods in response to permethrin exposure have been observed in other fish larvae (Xu et al. 2018). In our observations, only when paired with additional results including increased turning, meander, angular velocity, rotations, and anti-thigmotaxis does this lead to conclusions of bouts of twisting, away from the border area.

In contrast with the reactions during the light periods in permethrin exposure, the most notable differences in behaviors induced by chlorpyrifos exposure occurred during the dark periods. During Dark 1 of $72 \mathrm{~h}$ of exposure to $5 \mathrm{\mu g} \mathrm{l}^{-1}$ chlorpyrifos, the larvae moved erratically at the edges of the well, quantified by increased thigmotaxis and meander (Figs. 1B, 4B). Perhaps the behavior is indicative of exploration avoidance, as increased thigmotaxis is considered an indication of anxiety-like behavior (Schnörr et al. 2012). Then, in Dark 2 and Dark 3, the periods occurring after the stimulus periods of Light 1 and Light 2 , the larvae moved quickly for longer periods of time once the stimulus was removed, perhaps in a delayed reaction (Fig. 2B). The exertion of increased movement in response to the light stimulus could be overstimulating for the exposed fish, and the stress presented as hyperactivity (bursting, etc.) in the sequential dark periods.

We observed a wide range of behavioral effects when evaluating exposure to 2 different classes of compounds at environmentally relevant concentrations, suggesting that the LD cycle assay can be a sensitive tool to gather information possibly transferable to conservation efforts. For example, future studies exposing larvae to environmentally derived, aqueous grab samples could serve to elucidate sitespecific information, providing data on delta smeltspecific habitat viability. Because the delta smelt are progressively losing viable habitat due to anthropogenic factors, the ability to accurately assess habitat quality specific for this species is increasingly relevant for conservation efforts. In terms of the specific behaviors observed in the present study, behavior responses such as increased thigmotaxis, especially when observed with increased meander during chlorpyrifos exposure, could be advantageously used as test endpoints to evaluate the suitability of larval rearing habitats. If this behavior was performed for long periods in an aquaculture or environmental setting, this direction of movement could place pressure on the jaw, giving rise to craniofacial malformations, as this is a period of rapid growth. This type of outcome has been observed in aquaculture studies, including larval Anabas testudineus (climbing perch) housed in tanks of bright colors, that increased thigmotaxis, ultimately leading to jaw malformations (Ahmadi 2018). Outside of aquaculture, incidences of population-specific jaw malformations with unknown cause(s) have been observed in wild teleosts (Yamamoto et al. 2013).

Two of the most identifiably abnormal behaviors described in response to permethrin and chlorpyrifos (rapid twisting away from the well-edge, and erratic movement against the well-edge, respectively) occurred at environmentally relevant concentrations of pesticides. In an ecological context, the altered behavior observed in the present study could have population-level impacts. Behavioral abnormalities induced by environmental stress, including sublethal contaminant exposure, have been found to produce effects at the population and community levels in aquatic systems (Fleeger et al. 2003, Rohr \& Crumrine 2005, Söffker \& Tyler 2012). The indirect effects of behavioral abnormalities are often extrapolated to and studied as predator-prey interactions (Fleeger et al. 2003). For example, exposure to environmental stressors could potentially cause delta smelt living in the wild to be more susceptible to predation, or obstruct optimal prey acquisition. Experiments on juvenile delta smelt show that abnormal behavior caused by thermal stress correlates with increased predation by largemouth bass (Davis et al. 2019), a species invasive to the habitat of the delta smelt. Although no predator-prey interaction studies in the context of confounding environmental stress have been con- 
ducted on delta smelt larvae thus far, pyrethroids and organophosphates have been shown in the literature to be able to alter biological interactions in other teleost larvae. For example, increased predation risk occurred in fathead minnow larvae exposed to 0.455 and $1.142 \mu \mathrm{g} \mathrm{l}^{-1}$ esfenvalerate (a pyrethroid) (Floyd et al. 2008), and zebrafish larvae exposed to $2.2 \mu \mathrm{g} \mathrm{l}^{-1}$ chlorpyrifos were shown to be slower to habituate to a repetitive vibration stimulus (Faria et al. 2020).

Predation, without exacerbation from pesticide exposure, is already cited as a potential threat to the longevity of the delta smelt species (Hobbs et al. 2017). For example, the invasive fish species Menidia audens (Mississippi silverside) inhabits overlapping areas with delta smelt breeding and spawning grounds, and has been shown to prey on larval delta smelt (Schreier et al. 2016). The permethrin-induced hyperexcitability observed in the present study could have ecological impacts such as increased risk of predation due to inability to complete normal escape behavior. Because the role of larval escape response in predator-prey interactions is complex and context-dependent (Domenici 2010), more targeted studies would be necessary to fully assess the ecological impacts of the observed behavior in terms of predation. The high-throughput nature of the LD cycle assay can provide direction on which exposure concentrations to explore in more targeted studies.

Similarly, changes in abundance and distribution of prey (zooplankton) in the SFBD are predicted to play a role delta smelt declines (MacNally et al. 2010). It is generally accepted that the larval stage exists as one of the main bottlenecks predictive of the success of year classes within a fish stock, correlated with the ability to successfully obtain food in the critical time directly after yolk absorption (Leggett \& Deblois 1994, Houde 2008). Therefore, navigating prey capture confounded by pesticide-induced behavioral defects could potentially escalate the consequences of diminished prey availability.

Although delta smelt are currently difficult to find in the wild (Hobbs et al. 2017), having access to a cultured refuge population allows us to develop robust laboratory tests. This situation offers a unique opportunity to gather large amounts of information on a critically endangered species. The unique situation in which delta smelt larvae are able to be cultured and studied in the laboratory is one not afforded to all endangered teleost species. Considering the compounds evaluated are used worldwide, using tests developed on delta smelt larvae can possibly give rise to information applicable to other endangered teleost species which may encounter these compounds. Including behavioral endpoints in predictive models could strengthen risk assessments when evaluating the ecological impact of contaminants (Peterson et al. 2017).

Behavioral responses to permethrin were dose-dependent (Fig. S2) in the present study, in a quadratic or sigmoidal fashion during the light cycles at all time points. Non-monotonic dose-response relationships have been observed in older ( 43 d post hatch) delta smelt exposed to permethrin (Jeffries et al. 2015), in that the gene responses of smelt exposed to concentrations lower than the lowest observed effect concentration (LOEC; reported at $2.56 \mu \mathrm{g} \mathrm{l}^{-1}$ ) differed in directional changes from those at higher concentrations. Non-monotonic responses may occur for a variety of reasons, including mechanisms involving endocrine disruption. Considering that the metabolites of permethrin are more potent in terms of estrogenicity than the parent compound (Nillos et al. 2010), it could be possible that the ability to metabolize permethrin is increased at lower concentrations. The observation of non-monotonic dose-response patterns in permethrininduced behavior across the life stages of this nonmodel species can be informative to those designing experiments using other endangered or sensitive teleost species in terms of selection of dosing paradigms.

Although the response to the LD cycle assay is robust and consistent as currently studied, more investigation on the life history and general physiology of delta smelt larvae is needed in order to develop best practices for toxicological screenings. We found differences in responses between the control fish for the tested pesticides and postulate that this is likely influenced by seasonality. Two separate batches were used for each test, with permethrin tested on organisms from mid-season spawns, and chlorpyrifos conducted toward the end of the breeding season (Moyle et al. 2016). Differences in a spawn's reaction to environmental stressors across breeding seasons has been reported for other fish species (e.g. Atlantic cod Gadus morhua; Oomen \& Hutchings 2015).

The range of responses observed in the present study supports that the behavioral effects of permethrin or chlorpyrifos are dose-dependent, as well as time-dependent, and that they occur at environmentally realistic exposure concentrations. This also demonstrates the need to carefully consider the measured variable when evaluating the effects of contaminants on behavior. Contemplating all of the variables measured together in a holistic manner may help create a picture of behavior more relevant to physiological outcomes, as well as serve as an initial litmus test for compounds to investigate more thoroughly. 


\section{CONCLUSIONS}

Measuring a wide range of variables, and evaluating when they change throughout the LD cycle assay, allows a thorough documentation of behavioral effects due to sublethal exposure to contaminants. Because delta smelt larvae perform consistently in the LD cycle assay, and it is possible to glean minute behavioral differences within the test, the test can be applied to any number of compounds, allowing a 'behavioral library' to be built using consistent protocols and measurements. Considering that one of the goals in the conservation of the delta smelt is to reintroduce this endangered species into the wild, the results from this study and future studies can serve to inform conservation managers on the timing and location of potential effects relative to seasonality of contaminant application and presence in the SFBD. Although delta smelt play a niche role in a confined habitat, the ability to carry out in-depth behavioral studies may also give rise to information for other endangered teleost larvae that are not as easily accessible (e.g. not able to be cultured or maintained easily in the laboratory for a $96 \mathrm{~h}$ toxicology test).

Acknowledgements. We thank Luke Ellison, Galen Tigan, and all FCCL employees for providing the delta smelt larvae. We also thank Luann Wong and the Young Lab at UC Davis for assistance with chemical analyses, along with the dedicated volunteers who helped with larvae care and maintenance, including Meggie Carte, Celeste Valdivia, Claudia C. Mortyn, Hadeel Bader, and Nate Gonzalez. Funding was provided by the California Department of Fish and Wildlife (Proposition 1, grant P1796002 to R.E.C., S.M.B., N.A.F., and T.-C.H.), and from the Delta Stewardship Council (grant 18206 to S.M.B. and R.E.C.). This publication was also made possible by an National Institute of Environmental Health Sciences (NIEHS)-funded predoctoral fellowship (T32 ES007059 to P.C.M.) and the UC Davis Agricultural Experiment Station (2098-H to N.A.F.). Its contents are solely the responsibility of the authors and do not necessarily represent the official views of the NIEHS or NIH, nor those of other funding bodies.

\section{LITERATURE CITED}

Ahmadi (2018) Phototactic responses of climbing perch (Anabas testudineus) to various intensities and colors of LED underwater lamps: recommendation for future research. Adv Biol Earth Sci 3:114-129

Belden JB, Lydy MJ (2006) Joint toxicity of chlorpyrifos and esfenvalerate to fathead minnows and midge larvae. Environ Toxicol Chem 25:623-629

Brander SM, Jeffries KM, Cole BJ, Decourten BM and others (2016) Transcriptomic changes underlie altered egg protein production and reduced fecundity in an estuarine model fish exposed to bifenthrin. Aquat Toxicol 174: $247-260$
Brown LR, Komoroske LM, Wagner RW, Morgan-King T, May T, Connon RE, Fangue NA (2016) Coupled downscaled climate models and ecophysiological metrics forecast habitat compression for an endangered estuarine fish. PLOS ONE 11:e0146724

Cayan DR, Maurer EP, Dettinger MD, Tyree M, Hayhoe K (2008) Climate change scenarios for the California region. Clim Change 87:21-42

CDFW (California Department of Fish and Wildlife) (2018) State and federally listed endangered and threatened animals of California. In. California Department of Fish and Wildlife, The Natural Resources Agency. https:// nrm.dfg.ca.gov/FileHandler.ashx? DocumentID=109405

Cloern JE, Jassby AD (2012) Drivers of change in estuarinecoastal ecosystems: discoveries from four decades of study in San Francisco Bay. Rev Geophys 50:1-33

* Dach K, Yaghoobi B, Schmuck MR, Carty DR, Morales KM, Lein PJ (2019) Teratological and behavioral screening of the National Toxicology Program 91-Compound Library in zebrafish (Danio rerio). Toxicol Sci 167:77-91

*Davis BE, Hansen MJ, Cocherell DE, Nguyen TX and others (2019) Consequences of temperature and temperature variability on swimming activity, group structure, and predation of endangered delta smelt. Freshw Biol 64: 2156-2175

* Deanovic LA, Stillway M, Hammock BG, Fong S, Werner I (2018) Tracking pyrethroid toxicity in surface water samples: exposure dynamics and toxicity identification tools for laboratory tests with Hyalella azteca (Amphipoda). Environ Toxicol Chem 37:462-472

* Delgado-Moreno L, Lin K, Veiga-Nascimento R, Gan J (2011) Occurrence and toxicity of three classes of insecticides in water and sediment in two Southern California coastal watersheds. J Agric Food Chem 59:9448-9456

* DeMicco A, Cooper KR, Richardson JR, White LA (2010) Developmental neurotoxicity of pyrethroid insecticides in zebrafish embryos. Toxicol Sci 113:177-186

* Deng X (2017) Surface water monitoring for pesticides in agricultural areas of California, 2016. California Deparment of Pesticide Regulation. https://www.cdpr.ca.gov/ docs/emon/pubs/ehapreps/deng_report_304.pdf

*DiBartolomeis M, Kegley S, Mineau P, Radford R, Klein K (2019) An assessment of acute insecticide toxicity loading (AITL) of chemical pesticides used on agricultural land in the United States. PLOS ONE 14:e0220029

*Domenici P (2010) Context-dependent variability in the components of fish escape response: integrating locomotor performance and behavior. J Exp Zool Part A Ecol Genet Physiol 313:59-79

* Eaton DL, Daroff RB, Autrup H, Bridges J and others (2008) Review of the toxicology of chlorpyrifos with an emphasis on human exposure and neurodevelopment. Crit Rev Toxicol 38:1-125

Faria M, Wu X, Luja-Mondragón M, Prats E, Gómez-Oliván LM, Piña B, Raldúa D (2020) Screening anti-predator behaviour in fish larvae exposed to environmental pollutants. Sci Total Environ 714:136759

Fleeger JW, Carman KR, Nisbet RM (2003) Indirect effects of contaminants in aquatic ecosystems. Sci Total Environ 317:207-233

* Floyd EY, Geist JP, Werner I (2008) Acute, sublethal exposure to a pyrethroid insecticide alters behavior, growth, and predation risk in larvae of the fathead minnow (Pimephales promelas). Environ Toxicol Chem 27: 1780-1787 
Frank DF, Brander SM, Hasenbein S, Harvey DJ, Lein PJ, Geist J, Connon RE (2019) Developmental exposure to environmentally relevant concentrations of bifenthrin alters transcription of $\mathrm{mTOR}$ and ryanodine receptordependent signaling molecules and impairs predator avoidance behavior across early life stages in inland silversides (Menidia beryllina). Aquat Toxicol 206:1-13

* Gammon DW, Liu Z, Chandrasekaran A, El-Naggar SF, Kuryshev YA, Jackson S (2019) Pyrethroid neurotoxicity studies with bifenthrin indicate a mixed Type I/II mode of action. Pest Manag Sci 75:1190-1197

Giesy JP, Solomon KR, Coats JR, Dixon KR, Giddings JM, Kenaga EE (1999) Chlorpyrifos: ecological risk assessment in North American aquatic environments. In: Ware GW (ed) Reviews of environmental contamination and toxicology. Springer, New York, p 1-129

Glickman AH, Lech JJ (1981) Hydrolysis of permethrin, a pyrethroid insecticide, by rainbow trout and mouse tissues in vitro: a comparative study. Toxicol Appl Pharmacol 60:186-192

Hobbs JA, Moyle PB, Fangue N, Connon RE (2017) Is extinction inevitable for delta smelt and longfin smelt? An opinion and recommendations for recovery. San Fr Estuary Watershed Sci 15:2

Houde ED (2008) Emerging from Hjort's shadow. J Northwest Atl Fish Sci 41:53-70

*Hughes MF, Ross DG, Starr JM, Scollon EJ, Wolansky MJ, Crofton KM, Devito MJ (2016) Environmentally relevant pyrethroid mixtures: a study on the correlation of blood and brain concentrations of a mixture of pyrethroid insecticides to motor activity in the rat. Toxicology 359-360: 19-28

Jeffries KM, Komoroske LM, Truong J, Werner I and others (2015) The transcriptome-wide effects of exposure to a pyrethroid pesticide on the Critically Endangered delta smelt Hypomesus transpacificus. Endang Species Res 28: 43-60

Jin Y, Liu Z, Peng T, Fu Z (2015) The toxicity of chlorpyrifos on the early life stage of zebrafish: a survey on the endpoints at development, locomotor behavior, oxidative stress and immunotoxicity. Fish Shellfish Immunol 43:405-414

* Jokanović M, Kosanović M (2010) Neurotoxic effects in patients poisoned with organophosphorus pesticides. Environ Toxicol Pharmacol 29:195-201

Kassambara A (2020) Rstatix: Pipe-friendly framework for basic statistical tests. R package version 0.5.0.999. https:// rpkgs.datanovia.com/rstatix/

Kuivila KM, Hladik ML, Ingersoll CG, Kemble NE and others (2012) Occurrence and potential sources of pyrethroid insecticides in stream sediments from seven U.S. metropolitan areas. Environ Sci Technol 46:4297-4303

* Leggett WC, Deblois E (1994) Recruitment in marine fishes: Is it regulated by starvation and predation in the egg and larval stages? Neth J Sea Res 32:119-134

* Lenth R (2019) Emmeans: estimated marginal means, aka least-squares means. R package version 1.4.3.01. https:// cran.r-project.org/package=emmeans

Lessard J, Cavallo B, Anders P, Sommer T and others (2018) Considerations for the use of captive-reared delta smelt for species recovery and research. San Fr Estuary Watershed Sci 16:1-15

Levin ED, Addy N, Baruah A, Elias A, Christopher NC, Seidler FJ, Slotkin TA (2002) Prenatal chlorpyrifos exposure in rats causes persistent behavioral alterations. Neurotoxicol Teratol 24:733-741
Lindberg JC, Tigan G, Ellison L, Rettinghouse T, Nagel MM, Fisch KM (2013) Aquaculture methods for a genetically managed population of endangered delta smelt. N Am J Aquacult 75:186-196.

Mackay D, Giesy JP, Solomon KR (2014) Fate in the environment and long-range atmospheric transport of the organophosphorus insecticide, chlorpyrifos and its oxon. In: Giesy JP, Solomon KR (eds) Reviews of environmental contamination and toxicology, Vol 231. Springer, New York, NY, p 35-76

MacNally R, Thomson JR, Kimmerer WJ, Feyrer F and others (2010) Analysis of pelagic species decline in the upper San Francisco Estuary using multivariate autoregressive modeling (MAR). Ecol Appl 20:1417-1430

*Miller GW, Chandrasekaran V, Yaghoobi B, Lein PJ (2018) Opportunities and challenges for using the zebrafish to study neuronal connectivity as an endpoint of developmental neurotoxicity. Neurotoxicology 67:102-111

Millot S, Begout ML, Chatain B (2009) Exploration behaviour and flight response toward a stimulus in three sea bass strains (Dicentrarchus labrax L.). Appl Anim Behav Sci 119:108-114

* Moyle PB, Brown LR, Durand JR, Hobbs JA (2016) Delta smelt: life history and decline of a once-abundant species in the San Francisco Estuary. San Fr Estuary Watershed Sci 14:6

*Mundy PC, Carte MF, Brander SM, Hung T, Fangue NA, Connon RE (2020) Bifenthrin exposure causes hyperactivity in early larval stages of an endangered fish species at concentrations that occur during their hatching season. Aquat Toxicol 228:105611

*Nillos MG, Chajkowski S, Rimoldi JM, Gan J, Lavado R, Schlenk D (2010) Stereoselective biotransformation of permethrin to estrogenic metabolites in fish. Chem Res Toxicol 23:1568-1575

Nunes MEM, Schimith LE, Cost-Silva DG, Leandro LP and others (2020) Acute zebrafish embryonic exposure to permethrin induces behavioral changes related to anxiety and aggressiveness in adulthood. J Psychiatr Res 212:91-100

\% Oomen RA, Hutchings JA (2015) Variation in spawning time promotes genetic variability in population responses to environmental change in a marine fish. Conserv Physiol 3: $\operatorname{cov} 027$

* Peterson EK, Buchwalter DB, Kerby JL, Lefauve MK, VarianRamos CW, Swaddle JP (2017) Integrative behavioral ecotoxicology: bringing together fields to establish new insight to behavioral ecology, toxicology, and conservation. Curr Zool 63:185-194

R Core Team (2019) R: A language and environment for statistical computing. R Foundation for Statistical Computing, Vienna

Ramos S, Amorim E, Elliott M, Cabral H, Bordalo AA (2012) Early life stages of fishes as indicators of estuarine ecosystem health. Ecol Indic 19:172-183

Kichendrfer H, Creton R (2015) Chlorpyrifos and malathion have opposite effects on behaviors and brain size that are not correlated to changes in AChE activity. Neurotoxicology 49:50-58

Kichendrfer H, Pelkowski SD, Colwill RM, Créton R (2012) Developmental sub-chronic exposure to chlorpyrifos reduces anxiety-related behavior in zebrafish larvae. Neurotoxicol Teratol 34:458-465

* Rohr JR, Crumrine PW (2005) Effects of an herbicide and an insecticide on pond community structure and processes. Ecol Appl 15:1135-1147 
Sastre S, Torija CF, Pertusa IA, Beltrán EM, Pablos MV, González-doncel M (2018) Stage-dependent effects of chlorpyrifos on medaka (Oryzias latipes) swimming behavior using a miniaturized swim flume. Aquat Toxicol 200:37-49

Schnörr SJ, Steenbergen PJ, Richardson MK, Champagne DL (2012) Measuring thigmotaxis in larval zebrafish. Behav Brain Res 228:367-374

Schreier BM, Baerwald MR, Conrad JL, Schumer G, May B (2016) Examination of predation on early life stage delta smelt in the San Francisco Estuary using DNA diet analysis. Trans Am Fish Soc 145:723-733

Sharma S, Coombs S, Patton P, Perera TB De (2009) The function of wall-following behaviors in the Mexican blind cavefish and a sighted relative, the Mexican tetra (Astyanax). J Comp Physiol 195:225-240

Soderlund DM (2012) Molecular mechanisms of pyrethroid insecticide neurotoxicity: recent advances. Arch Toxicol 86:165-181

Söffker M, Tyler CR (2012) Endocrine disrupting chemicals and sexual behaviors in fish a critical review on effects and possible consequences. Crit Rev Toxicol 42:653-668

Solomon KR, Williams WM, Mackay D, Purdy J, Giddings JM, Giesy JP (2014) Properties and uses of chlorpyrifos in the United States. In: Giesy JP, Solomon KR (eds) Reviews of environmental contamination and toxicology, Vol 231. Springer, New York, NY, p 13-34

Steele WB, Kristofco LA, Corrales J, Saari GN and others (2018) Comparative behavioral toxicology with two common larval fish models: exploring relationships among modes of action and locomotor responses. Sci Total Environ 640-641:1587-1600

Tang W, Wang D, Wang J, Wu Z, Li L, Huang M, Xu S (2018) Pyrethroid pesticide residues in the global environment: an overview. Chemosphere 191:990-1007

USFWS (US Fish and Wildlife Service) (1993) Endangered and threatened wildlife and plants: determination of threatened status for the delta smelt. Fed Regist 58 (42):12854-12684. https://www.biologicaldiversity.org/ species/fish/Delta_smelt/pdfs/fr2235.pdf

Wang D, Weston DP, Lydy MJ (2009) Method development for the analysis of organophosphate and pyrethroid insecticides at low parts per trillion levels in water. Talanta 78:1345-1351

Editorial responsibility: Brendan Godley, University of Exeter, Cornwall Campus, UK
Weston DP, Lydy MJ (2012) Stormwater input of pyrethroid insecticides to an urban river. Environ Toxicol Chem 31: 1579-1586

*Weston DP, Asbell AM, Lesmeister SA, Teh SJ, Lydy MJ (2014) Urban and agricultural pesticide inputs to a critical habitat for the threatened Delta smelt (Hypomesus transpacificus). Environ Toxicol Chem 33:920-929

*Weston DP, Chen D, Lydy MJ (2015a) Stormwater-related transport of the insecticides bifenthrin, fipronil, imidacloprid, and chlorpyrifos into a tidal wetland, San Francisco Bay, California. Sci Total Environ 527-528:18-25

*Weston DP, Schlenk D, Riar N, Lydy MJ, Brooks ML (2015b) Effects of pyrethroid insecticides in urban runoff on Chinook salmon, steelhead trout, and their invertebrate prey. Environ Toxicol Chem 34:649-657

Weston DP, Moschet C, Young TM, Johanif N, Poynton HC, Major KM, Connon RE, Hasenbein S (2019) Chemical and toxicological effects on cache slough after storm-driven contaminant inputs. San Fr Estuary Watershed Sci $17: 3$

Williams WM, Giddings JM, Purdy J, Solomon KR, Giesy JP (2014) Exposures of aquatic organisms to the organophosphorus insecticide, chlorpyrifos resulting from use in the United States. In: Giesy JP, Solomon KR (eds) Reviews of environmental contamination and toxicology. Springer, New York, NY, p 77-118

* Xu C, Li X, Jin M, Sun X, Niu L, Lin C, Liu W (2018) Early life exposure of zebrafish (Danio rerio) to synthetic pyrethroids and their metabolites: a comparison of phenotypic and behavioral indicators and gene expression involved in the HPT axis and innate immune system. Environ Sci Pollut Res 25:12992-13003

Y Yamamoto S, Morita K, Yokoyama R, Miyamoto K, Sato M, Maekawa K (2013) Incidence of a skeletal deformity (truncated upper jaw) in an isolated population of whitespotted charr Salvelinus leucomaenis. J Ichthyol 53: 889-893

*You J, Lydy MJ (2006) Pyrethroid insecticides and sediment toxicity in urban creeks from California and Tennessee. Environ Sci Technol 40:1700-1706

* Zhang X, Starner K, Spurlock F (2012) Analysis of chlorpyrifos agricultural use in regions of frequent surface water detections in California, USA. Bull Environ Contam Toxicol 89:978-984

Submitted: April 27, 2020; Accepted: November 5, 2020 Proofs received from author(s): January 29, 2020 